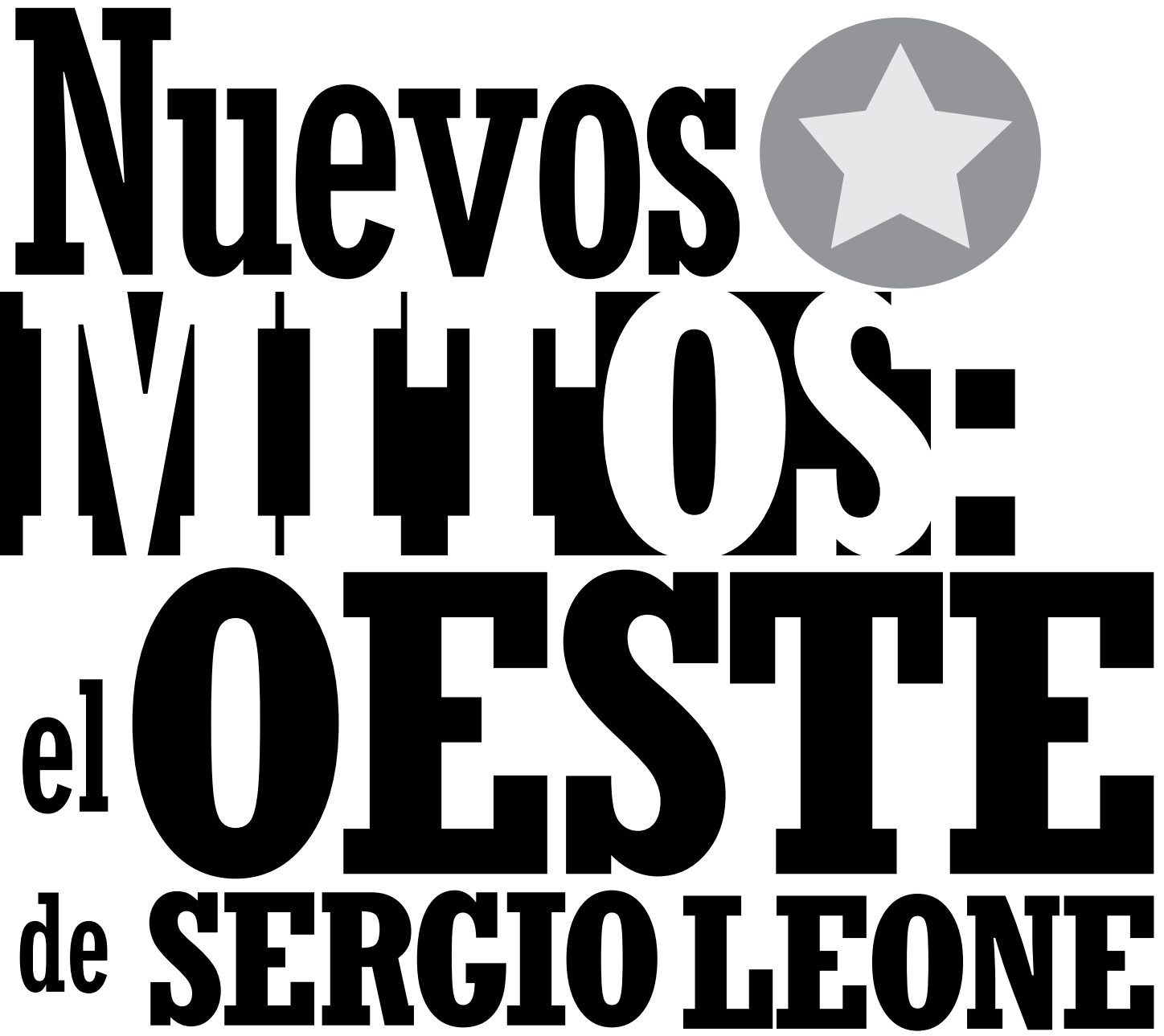

En lo que supone una revalorización de su obra en tiempos recientes, el tratamiento de Leone sobre uno de los géneros más longevos del cine plantea una retórica alternativa. Una desmitificación que, irónicamente, creó una nueva mitología, moralmente ambigua y marcada por la violencia. Encarnada en dos películas concretas, El bueno, el malo y el feo (1966) y Érase una vez en el Oeste (1968), esta "antirretórica" propone una reformulación casi total de las convenciones previas del género. 
El bueno, el malo y el feo 4 Fuente: elpelicultista.com

..n.t. 
Como género de ficción, el wéstern ha demostrado ser un verdadero sobreviviente. Ya en la época del cine mudo se consolidó como un género recurrente, usualmente grabado en estudio, regla que se empezó a quebrar hacia los años treinta y cuarenta, con una producción sistemática y mecánica en exteriores. El público veía en celuloide la confirmación de muchos de sus discursos culturales: pistoleros a ambos lados de la ley que se enfrentaban, si no entre ellos, a la difícil labor de pacificar el territorio salvaje de los sioux, los kiowas y los utes, encarnando el espíritu pseudoreligioso del "destino manifiesto".

El discurso de dominación de la naturaleza (civilización contra salvajismo) es un elemento recurrente en las primeras décadas del género que quizá llegó a su punto máximo de ambigüedad y reflexión con Más corazón que odio (The Searchers, 1956), filme de John Ford con John Wayne, el vaquero por excelencia, estrenado ya en el crepúsculo de la época dorada del género. Otra forma de conflicto común era el enfrentamiento físico de individuos en roles clara y diametralmente antagónicos. El "bueno" es por lo general un pistolero al servicio de la ley que protege a su pueblo, hombre de familia, seguro de sí, firme, justo y cristiano. El "malo" viene a ser su antítesis: un hombre dado al crimen, cínico, violento, con un sentido del deber que versa siempre y solo alrededor de lo que le es conveniente, sin mayores reparos en lo que ello significa para los demás. El wéstern clásico es uno de esos géneros en donde el bien y el mal se enfrentan directa y claramente, en parte porque es sencillo identificar quién es el malo y quién el bueno.

Esta clara distinción moral se relativiza en los wésterns italianos. Aparte de Leone, los personajes de las películas de Sergio Corbucci, Mario Bava, Enzo Castellari o Alberto Cardone eran por lo general bandidos y mercenarios, llamados a desenfundar sus armas en ambientes tan hostiles como ellos. Buscaban dinero, oro y sobre todo venganza, no paz y orden. En películas como Django (Sergio Corbucci, 1966), Baño de sangre al salir el sol (Alber- to Cardone, 1966) y ¿Por qué seguir matando? (José Antonio de la Loma y Edoardo Mulargia, 1965), la pacificación del pueblo es el discurso que encubre una historia de retribución personal y hace todo lo posible por darle un matiz heroico al protagonista: de vengador a salvador. En el caso de El mercenario (1968) de Sergio Corbucci, la revolución llevada a cabo por Paco rápidamente deviene en una oportunidad para robar $\mathrm{y}$ asesinar, como menciona en su momento el mercenario del título Sergei Kowalski (Franco Nero).

Pocos periodos de la historia han sido visitados con tanta frecuencia, $\mathrm{y}$, pese a ello, poco de lo que vemos se ajusta a la realidad exacta. Y este rasgo es común tanto en americanos como en italianos. Registros históricos confirman que cargar un arma en público en poblados de Utah, Colorado o Nuevo México estaba prohibido, y que los tiroteos como el de O.K. Corral y los grandes robos de bancos al lomo de alazanes eran escasos. Los filmes de Ford y Leone tratan sobre un determinado mundo alterno, inspirado en los estados al oeste del río

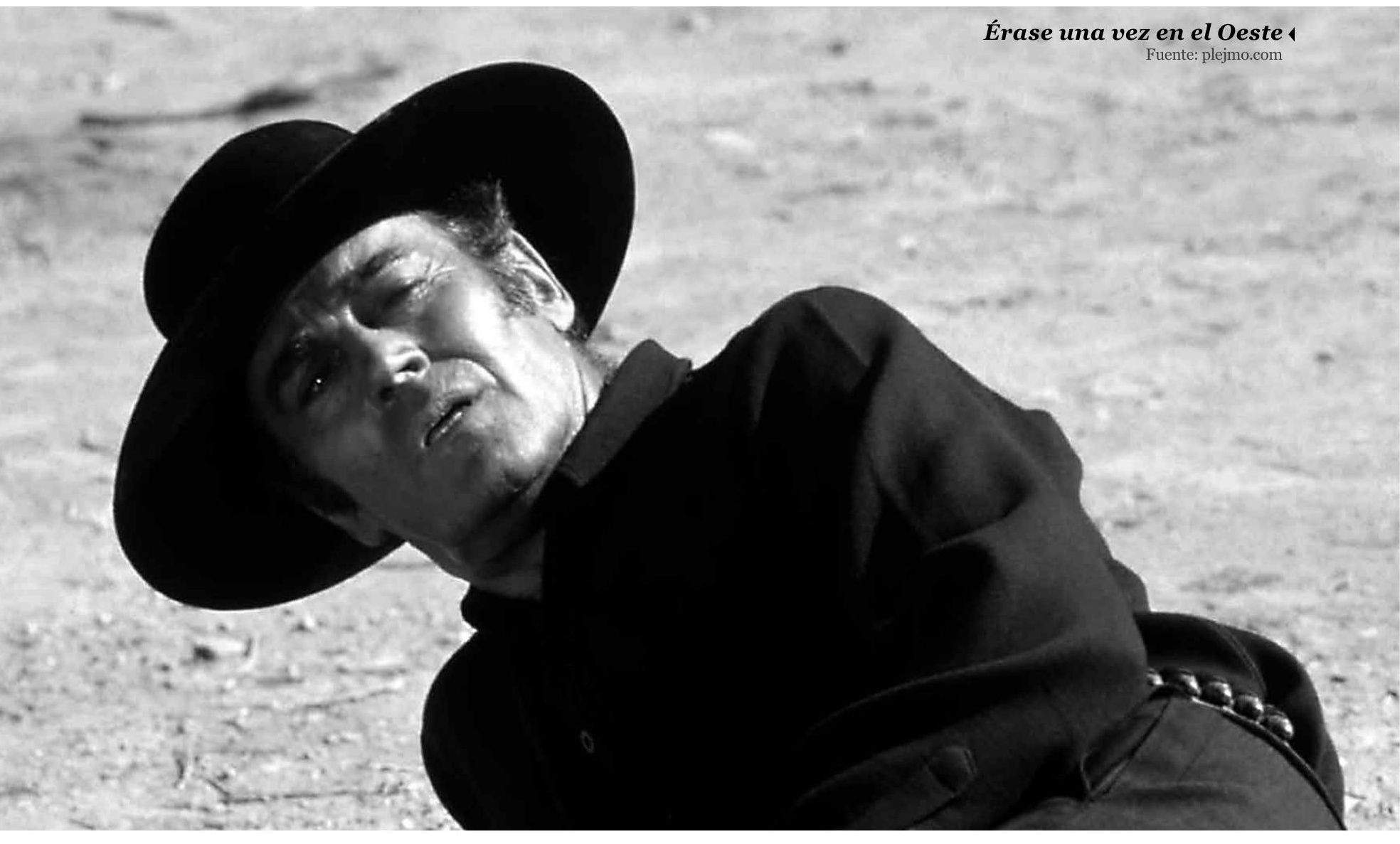


Mississippi del siglo XIX, pero cuyos valores, personajes y locaciones estaban bastante alterados, ya fuera por decisiones del director o por las expectativas de su audiencia.

Pese a que ya se habían rodado wésterns en Europa como El tesoro del Lago de la Plata (Der Schatz im Silbersee, 1961) de Harald Reinl, lo que diferenciaba a Leone era su marcado estilo visual, libre de los valores clásicos fordianos y cuyos guiones lograban una síntesis entre el hecho histórico y la imaginación. Para el momento en que Leone dirige su primer wéstern, ya con diecisiete años en la industria, sabía que mucho de lo que veía de niño en el cine sobre la conquista del Oeste era falso. Esta realización le servía para justificar las libertades creativas que él también se daría. A fin de cuentas, el lenguaje audiovisual (como el verbal) no supone una representación fiel del mundo, por más que esto se plantee hacer. En el lenguaje todo es convención, figuración y, en última instancia, una muy creíble ilusión. Tanto en El bueno, el malo y el feo (1966) como en Érase una vez en el Oeste (1968), la precisión histórica es selectiva, presente al momento de recrear las locaciones, el vestuario, las armas, etc., pero deliberadamente anulada en lo que respecta a, por ejemplo, el sistema de recompensas, las funciones del sheriff, los ahorcamientos, etc. Es esta volátil mezcla de realismo con mito lo que mejor define su propuesta audiovisual: Leone logró reemplazar viejos paradigmas genéricos con los suyos propios, ejerciendo una influencia que lleva más de medio siglo y que trascendió al mismo género.

\section{Oportunismo salvaje}

La historia narrada en El bueno, el malo y el feo abunda en personajes y escenarios, aunque la misión del trío protagonista es invariable. Con casi tres horas de duración, los protagonistas se ven forzados a pactar y terminar alianzas según ven conveniente, ya sea entre ellos o con algún otro personaje. El hecho de que Eastwood sea "el bueno" no dice nada sobre su ética o sus valores. En comparación con sus rivales/aliados, no es superior en el sentido moral del término, tan solo es más astuto y dispara mejor. A diferencia de los wésterns americanos, los valores morales universales que separaban al héroe del antagonista se hallan ausentes. Blondie, como muchos otros, miente, traiciona, engaña y asesina a todo el que entorpezca su misión, siendo menos despiadado que Van Cleef y más inteligente que Wallach. Los motivos dejan de ser ideales abstractos; queda solamente la codicia y el puro oportunismo, pasando de confederados a unionistas según cuál bando los acerque más a su meta, mientras que sus principios morales permanecen ambiguos.

No obstante, el filme sí asume una postura respecto a la Guerra Civil de los Estados Unidos. Salvo por el Capitán Harper (Antonio Molino), que advierte a Ojos de Ángel sobre no maltratar a los prisioneros de la Confederación, los personajes del ejército de la Unión son presentados como torturadores, inclementes y borrachos. El rol que asumen los confederados suele ser mucho más desfavorable, principalmente como hombres moribundos y prisioneros de guerra. Hasta aquí hay claramente una toma de posición, señalando quiénes son las víctimas y quiénes los victimarios. Esto cambia en la escena de la batalla del puente, antes de que Blondie y Tuco lleguen al cementerio de Sad Hill. Lejos del combate, Clint Eastwood habla por ambos bandos de la guerra cuando dice nunca haber visto semejante desperdicio de vidas humanas.

Mediante sus personajes, Leone toma la postura de un observador paciente, ajeno al conflicto, un extranjero capaz de experimentar compasión. Contrario al discurso oficial estadounidense, Leone se dio cuenta de que en una guerra civil nunca hay ganadores, solo algunos que pierden menos que otros, certeza complementaria a la ambigüedad de la figura del héroe, salvador para un bando $y$ asesino para el otro.

El simbolismo antibélico alcanza su máxima representación en el duelo final. Los ex socios Blondie, Ojos de Ángel y Tuco se enfrentan por el oro, rodeados por las tumbas de soldados cuyas muertes a ellos los tienen sin cuidado. Por un breve instante la guerra se hace personal, importando solo la eliminación del rival y el premio mayor. Eventualmente Blondie gana, asesinando a Ojos de Ángel y humillando a Tuco, cabalgando al horizonte con cien mil dólares en monedas de oro. El hecho es que detrás de la fortuna de uno (Blondie) se hallan miles de hombres, pobres y muertos, principio aplicable a cualquier guerra. Sobre sus tumbas (literalmente), tres individuos se enfrentan por algo de fortuna. Fuera de todo orden y ley, el oportunismo es el principio rector de los hombres fuertes. En este punto, la película describe la guerra lejos del idealismo patriótico con el cual muchos estadounidenses, aún hoy, se refieren a ciertas etapas de su historia.

\section{De amos y esclavos}

Diferenciándose de otros wésterns de la época por su larga duración, tono y estética, en Érase una vez en el Oeste Leone presenta una mirada contemplativa y reivindicadora, centrada en la figura del poderoso contra el débil. El amo que, contra todo pronóstico, es derrotado por el esclavo. En efecto, a diferencia de la trilogía del dólar, son las víctimas, los sometidos, los débiles los que toman un rol central. Los personajes de Jill (Claudia Cardinale) y Cheyenne (Jason Robards) son perdedores por naturaleza. Complementario a ellos, yace el personaje de Charles Bronson, apodado Armónica en la película, quien años antes ya había sufrido abusos similares por causa del mismo hombre: Frank (Henry Fonda). Volverse en contra de su opresor, de su amo, supone un mero acto cognoscitivo, encarnado en el deseo de venganza, y que en un segundo momento da paso al acto concreto del castigo. Al principio de la película, Armónica ya ha tomado esa primera decisión, la misma voluntad luego brota en sus coprotagonistas y se le unen en su búsqueda de justicia. El resto de la historia es la realización material de su voluntad: la venganza, la muerte, el último y máximo ajuste de cuentas.

Complementarias a esto se tienen disputas más pequeñas, pero igual de importantes. Las luchas por el poder no se limitan al juego clásico de "buenos" contra "malos": se dan también al interior de esos bandos imaginarios. Morton, debilitado por 
de la identidad real del asesino de su familia (Frank), revelación hecha posible por Armónica. De ahí en más, la postura de la viuda será de resistencia, coraje y esperanza. Las relaciones tradicionales del wéstern se invierten una vez más: tanto Bronson como Robards quedan subordinados a la protección de Jill, que a su vez resguarda la voluntad de la familia McBain. Quizá queriendo reivindicar la ausencia femenina en sus trabajos previos, Leone le da a la figura de la mujer un rol central para trama.

\section{El nuevo mito del Oeste}

La deconstrucción de idealismos era algo con lo que el director había tenido una experiencia bastante próxima. Refiriéndose a su encuentro con soldados norteamericanos en la liberación de Italia en 1943, Leone recalcó lo siguiente:

En mi infancia, América era como una religión. [...] Luego, americanos de verdad entraron a mi vida y perturbaron todos mis sueños. [...] No eran los americanos del Oeste, sino soldados como cualquier otro, [...] materialistas, posesivos, interesados en placeres y bienes terrenales (Edwards, 2002, párrafo 18).

Hay una noción clarísima que deja su producción cinematográfica entre 1964 y 1968: el Oeste no fue el triunfo de una voluntad expansionista, romántica y patriótica. Fue la fundación de un país hecho por hombres ambiciosos y violentos, sí, pero también por personas corrientes que buscaban individualmente reinventar sus vidas, lo cual explica la fiebre del oro y las migraciones a California, o el éxodo mormón que ayudó a poblar el actual estado de Utah. Leone no destruye solamente una retórica oficial: sin proponérselo, instaura una nueva mitología. Aún lejos de la precisión histórica, marcaría el desarrollo del género en las décadas siguientes.

Dan Edwards (2002), investigador de la Universidad de Melbourne, escribe lo siguiente:

Leone representó América lejos de toda retórica, aparte de la del interés propio y un individualismo asesino. Pese a todas sus libertades históricas, sus películas parecen encarnar ciertas verdades esenciales respecto a las apelaciones ilícitas de la mitología fundacional americana, en un modo que pocas, si acaso alguna película americana ha hecho jamás (párrafo 21).

Más allá de su particular estilo visual (los primerísimos primeros planos, la música de Ennio Morricone, lentes de cámara amplísimos, etc.), su herencia se dejó ver en la temática y el tono que otras películas, ya no solo italianas ni wésterns, decidieron emplear en la última mitad del siglo XX. Revisar su obra es crucial para entender a George Roy Hill, Sam Peckinpah, Robert Aldrich o Don Siegel, quienes en los sesenta y setenta empezaron a adoptar estéticas basadas en los nuevos paradigmas que Leone había forjado.

Cabe mencionar los filmes que en su momento haría Clint Eastwood, como La venganza del muerto (High Plains Drifter, 1973), El fuera de la ley (The Outlaw Josey Wales, 1976), o El jinete pálido (Pale Rider, 1985). Presentando a criminales, asesinos y caza recompensas como protagonistas, así como por la ambigüedad de las nociones de justicia y moral, Eastwood mostraba en esta fase de su carrera una influencia clara de su maestro. Incluso en películas que no pertenecen al género, como la saga de Harry, el sucio (1973-1988), sobreviven algunos rasgos elementales: la figura del justiciero, la ambigüedad moral, la violencia. Irónicamente, sería el mismo Eastwood quien se revelaría contra Leone al filmar Sin perdón (Unforgiven, 1992), exponiendo un destino probable y perturbador para los mercenarios que años antes tomaron las riendas del género.

Años después, Quentin Tarantino ha demostrado ser uno de los directores más directamente tocados por esta influencia. Tarantino, quien en su momento llamó a El bueno, el malo y el feo "el mayor logro de la historia del cine" (Buckmaster. 2016), recreó sin reservas la escena inicial de este filme en Bastardos sin gloria (Inglorious Basterds, 2009) y utilizó el tema "Il triello" de Ennio Morricone para Kill Bill Vol. 2 (2004).

Leone es en esencia un autor revisionista. Apelando a temáticas uni- versales como la venganza, la ambición y la lucha por el poder, comprobó que el género de John Wayne era capaz de englobar una multiplicidad de visiones estéticas, siempre y cuando se liberase del discurso retórico que su tradición clásica le imponía. En años futuros otros autores aprovecharían sabiamente este potencial: Alejandro Jodorowsky con El topo (1970), Viktor Tregubovich con Dauria (1972), Jim Jarmusch en Dead Man (1991), o Hans Matos Camac en Pueblo Viejo (2015), e incluso fusiones con otros géneros como en Sin lugar para los débiles (No Country for Old Men, hermanos Coen, 2007), En un lugar sin ley (Ain't Them Bodies Saints, David Lowery, 2013) y Nada que perder (Hell or High Water, David Mackenzie, 2016).

En un camino iniciado con Por un puñado de dólares (Per un pugno di dollari, 1964), Leone fue el primero en darse cuenta de que el wéstern no se limitaba a un momento histórico: había evolucionado en una estética propia, adaptable bajo diferentes reglas. Se trata de un salto cualitativo al cual puede atribuirse su supervivencia hasta nuestros días y que liberó el género a las miradas estéticas y temáticas de directores posteriores.

\section{REFERENCIAS}

Buckmaster, L. 2016. The lasting legacy of The Good, the Bad and the Ugly. BBC. Recuperado de http://www.bbc.com/culture/story/20160210the-lasting-legacy-of-the-good-the-bad-andthe-ugly

Edwards, D. 2002. Sergio Leone. Senses of Cinema. Recuperado de http://sensesofcinema. com/2002/great-directors/leone/

Frayling, C. 2006. Spaghetti Westerns: Cowboys and Europeans from Karl May to Sergio Leone. Londres, Reino Unido: IB Tauris.

Guzmán Parra, V., y Vila Oblitas, J. R. 2010. Influencia del spaghetti-western en malditos bastardos de Quentin Tarantino. Área Abierta, (26)1.

McClain, W. 2010. Western, Go Home! Sergio Leone and the "Death of the Western" in American Film Criticism. Journal of Film and Video, 62(1), 52-66.

Zurro, J. 2014. 25 años sin Sergio Leone, el plagiador que reinventó el cine. El confidencial. Recuperado de http://www.elconfidencial. com/cultura/cine/2014-05-01/25-anos-sinsergio-leone-el-plagiador-que-reinvento-elcine_123631/ 